\title{
Preoperative interscalene brachial plexus block aids in perioperative temperature management during arthroscopic shoulder surgery
}

\author{
Se Hun Lim, Wonjin Lee, JaeGwan Park, Myoung-hun Kim, Kwangrae Cho, \\ Jeong Han Lee, Soon Ho Cheong, and Kun Moo Lee \\ Department of Anesthesiology and Pain Medicine, Busan Paik Hospital, Inje University College of Medicine, Busan, \\ Korea
}

Background: Hypothermia is common during arthroscopic shoulder surgery under general anesthesia, and anestheticimpaired thermoregulation is thought to be the major cause of hypothermia. This prospective, randomized, double-blind study was designed to compare perioperative temperature during arthroscopic shoulder surgery with interscalene brachial plexus block (IBPB) followed by general anesthesia vs. general anesthesia alone.

Methods: Patients scheduled for arthroscopic shoulder surgery were randomly allocated to receive IBPB followed by general anesthesia (group GB, $\mathrm{n}=20$ ) or general anesthesia alone (group GO, $\mathrm{n}=20$ ), and intraoperative and postoperative body temperatures were measured.

Results: The initial body temperatures were $36.5 \pm 0.3^{\circ} \mathrm{C}$ vs. $36.4 \pm 0.4^{\circ} \mathrm{C}$ in group $\mathrm{GB}$ vs. $\mathrm{GO}$, respectively $(\mathrm{P}=0.215)$. The body temperature at 120 minutes after induction of anesthesia was significantly higher in group GB than in group $\mathrm{GO}\left(35.8 \pm 0.3^{\circ} \mathrm{C}\right.$ vs. $\left.34.9 \pm 0.3^{\circ} \mathrm{C} ; \mathrm{P}<0.001\right)$. The body temperatures at 60 minutes after admission to the post-anesthesia care unit were $35.8 \pm 0.3^{\circ} \mathrm{C}$ vs. $35.2 \pm 0.2^{\circ} \mathrm{C}$ in group $\mathrm{GB}$ vs. $\mathrm{GO}$, respectively $(\mathrm{P}<0.001)$. The concentrations of desflurane at 0,15 , and 120 minutes after induction of anesthesia were 6.0 vs. $6.0 \%(\mathrm{P}=0.330), 5.0 \pm 0.8 \%$ vs. $5.8 \pm 0.4 \%(\mathrm{P}=$ $0.001)$, and $3.4 \pm 0.4 \%$ vs. $7.1 \pm 0.9 \%(\mathrm{P}<0.001)$ in group GB vs. GO, respectively.

Conclusions: The present study demonstrated that preoperative IBPB could reduce both the intraoperative concentration of desflurane and the reduction in body temperature during and after arthroscopic shoulder surgery.

Key Words: Arthroscopy, Brachial plexus block, General anesthesia, Shoulder, Temperature.

Corresponding author: Kun Moo Lee, M.D., Ph.D.

Department of Anesthesiology and Pain Medicine, Busan Paik Hospital, Inje University College of Medicine, 75, Bokji-ro, Busanjingu, Busan 47392, Korea

Tel: 82-51-890-6520, Fax: 82-51-898-4216

E-mail: aneslkm@inje.ac.kr

Received: February 29, 2016.

Revised: 1st, April 6, 2016; 2nd, April 22, 2016.

Accepted: April 22, 2016.

Korean J Anesthesiol 2016 August 69(4): 362-367

http://dx.doi.org/10.4097/kjae.2016.69.4.362

\section{Introduction}

Arthroscopic shoulder surgery is commonly performed under general anesthesia, and perioperative hypothermia (core body temperature lower than $36^{\circ} \mathrm{C}$ ) commonly occurs [1-3]. Even mild perioperative hypothermia (decrease in core body temperature of 1 to $2^{\circ} \mathrm{C}$ ) can increase the incidence of major complications such as adverse cardiac events [4], decreased drug metabolism [5], increased blood loss and transfusion requirements [6], wound infections [7], and increased mortality [8].

(c) This is an open-access article distributed under the terms of the Creative Commons Attribution Non-Commercial License (http://creativecommons.org/ licenses/by-nc/4.0/), which permits unrestricted non-commercial use, distribution, and reproduction in any medium, provided the original work is properly cited. 
Hypothermia results from a combination of anesthetic-impaired thermoregulation and exposure to a cold operating room environment [9]. Of these two factors, anesthetic-impaired thermoregulation is much more important cause of hypothermia [9]. Volatile anesthetics impair thermoregulation in a dose-dependent and nonlinear manner [10-12], which means that greater concentrations produce disproportionate threshold reductions, leading to lower temperatures.

Interscalene brachial plexus block (IBPB) is commonly performed with a single injection or continuous catheter insertion during arthroscopic shoulder surgery for postoperative pain control [1]. When a brachial plexus block has been performed preoperatively, the concentrations of volatile anesthetics can be reduced during arthroscopic shoulder surgery. We hypothesized that lower concentrations of volatile anesthetics with brachial plexus block during arthroscopic shoulder surgery could result in decreased perioperative temperature reduction. This prospective, randomized, double-blind study was designed to compare the temperature in patients undergoing arthroscopic shoulder surgery with IBPB followed by general anesthesia (group GB) vs. general anesthesia alone (group GO).

\section{Materials and Methods}

Following approval from our hospital's Institutional Review Board, we enrolled 40 patients with American Society of Anesthesiologists physical status 1 or 2 who were scheduled to undergo shoulder arthroscopy under general anesthesia. Written, informed consents were obtained for all enrolled patients. Patients with a history of thyroid disease, dysautonomia, or Raynaud's syndrome, as well as those with contraindications to brachial plexus block, were excluded. Patients were instructed on how to use the device for intravenous patient-controlled analgesia (IVPCA) for postoperative pain management and how to report pain via the numeric rating scale (NRS) the day before surgery. Based on the results of a previous study [13], the present study was designed to enroll 20 subjects in each group, which would have $90 \%$ power to detect a difference in means of $0.7^{\circ} \mathrm{C}$ with a 0.05 two-sided significance level and allow up to $20 \%$ loss to follow-up. Patients were randomly allocated to receive general anesthesia alone (group GO) or IBPB followed by general anesthesia (group GB) using computerized random number generation.

No premedication was administered prior to anesthesia. When patients arrived at the preoperative holding area, the ambient temperature was $22-24^{\circ} \mathrm{C}$. Pre-warming was not used before the induction of anesthesia. A single well-trained anesthesiologist who was not involved in the study performed ultrasound-guided IBPB in the preoperative holding area for the patients of group GB. Before the initiation of IBPB, standard monitors were applied to patients and supplemental oxygen was administered at $2-3 \mathrm{~L} / \mathrm{min}$ via nasal cannula. Patients were positioned supine with the head turned 45 degrees to the contralateral side. After sterile preparation and draping of the injection area, the round or oval hypoechoic trunks were identified between the anterior and middle scalene muscles using ultrasound

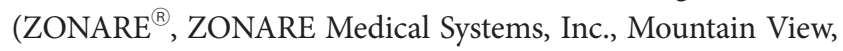
CA, USA). IBPB was performed at the lowest possible level in the neck with a disposable epidural needle (Dr. ${ }^{\circledR}$, Dr.Japan Co., Ltd., Tokyo, Japan) using an in-plane approach, and a perineural solution composed of $20 \mathrm{ml}$ of $0.5 \%$ levobupivacaine (100 mg) with $100 \mu \mathrm{g}$ of epinephrine was injected slowly after negative aspiration. After injection of the perineural solution, a blinded research assistant evaluated the degree of sensory and motor block every 5 minutes up to 30 minutes. The degree of sensory block was assessed with the pin-prick test in the median, ulnar, radial, and musculocutaneous nerve dermatomes. The degree of motor block was tested functionally in the distribution, along with thumb abduction and flexion of the elbow in supination. Block success was defined as the achievement of sensory loss and paresis or no movement in the median, ulnar, radial, and musculocutaneous nerve distributions within 30 minutes after IBPB.

The temperature of the operating room was maintained at $21-23^{\circ} \mathrm{C}$. On arrival in the operating room, patients were positioned in the supine position on the operating table. Monitoring devices such as electrocardiogram, pulse oximetry, non-invasive blood pressure, and bispectral index monitor BIS $^{\mathrm{TM}}, \mathrm{A}-2000$ monitor; Aspect Medical Systems, Natick, MA, USA) were attached to the patients. After a brief setting period, hemodynamic measurements were made to obtain baseline values, and measurements were then repeated every 3 minutes. Before the induction of anesthesia, initial body temperature was measured at the side opposite to the operation site with a tympanic thermometer (ThermoScan IRT 4020 ${ }^{\circledR}$, Braun GmbH, Kronberg, Germany). After the induction of anesthesia, core temperature was measured with an esophageal stethoscope with a temperature sensor (DeRoyal ${ }^{\circledR}$, DeRoyal Industries, Inc., Powell, TN, USA) every 15 minutes. General anesthesia was induced with propofol $2 \mathrm{mg} / \mathrm{kg}$ and rocuronium $0.6 \mathrm{mg} / \mathrm{kg}$ by an anesthesiologist blinded to group allocation. After endotracheal intubation, anesthesia was maintained with inhalation anesthetics using desflurane and a $50 \%$ oxygen $-\mathrm{N}_{2} \mathrm{O}$ mixture at a fresh gas flow rate of $3 \mathrm{~L} / \mathrm{min}$. Mechanical ventilation was controlled with a tidal volume of $8-10 \mathrm{ml} / \mathrm{kg}$ at a respiratory rate of $8-12$ breaths/min with no positive end-expiratory pressure, to maintain an end-tidal carbon dioxide concentration of $30-35 \mathrm{mmHg}$. The initial dial setting of Dräger D-Vapor vaporizers was $6 \%$. The BIS score was maintained at 40-60 and changes in hemodynamic variables were maintained within $\pm 20 \%$ of baseline 
values by changing the concentration of inhaled desflurane. The dial setting of Dräger D-Vapor vaporizers was monitored every 15 minutes. Rocuronium (5 mg) was injected for the prevention of any patient movement with the appearance of clefts in the capnogram which indicate spontaneous breathing effort during controlled mechanical ventilation. Lactated Ringer's solution at room temperature was used as the maintenance fluid. Warm cotton blankets were applied if the body temperature of a patient fell below $35^{\circ} \mathrm{C}$.

After the induction of anesthesia, patients were placed in the beach chair position. All of the shoulder arthroscopic surgeries were performed by the same orthopedic surgeon. Normal saline solution at room temperature $\left(21-22^{\circ} \mathrm{C}\right)$ in a $3 \mathrm{~L}$ bag, mixed with $1 \mathrm{mg} / \mathrm{ml}$ of epinephrine, was used as the irrigation fluid. The irrigation fluid was delivered to the arthroscope at a pressure of $60 \mathrm{mmHg}$ by a pressure-controlled pump.

After extubation, patients were admitted to the post-anesthesia care unit (PACU) for about an hour. The body temperature of patients was measured at the side opposite the operation site with a tympanic thermometer every 15 minutes. If the temperature fell below $35.5^{\circ} \mathrm{C}$, we applied active warming with a forcedair warmer (WarmTouch ${ }^{\circledR}$, Mallinckrodt Medical Inc., St Louis, MO, USA). Postoperative pain was evaluated using the NRS ( $0=$ no pain; $10=$ worst possible pain) 15 minutes after admission to the PACU. Mild, moderate, and severe pain were defined as NRS scores of 1 to 3,4 to 6 , and 7 to 10 , respectively. When patients experienced moderate to severe pain (NRS $>3$ ), they pushed a button on the IV-PCA device to receive a bolus dose of fentanyl, as instructed. The device was set to deliver a 10 to $20 \mu \mathrm{g}$ bolus of fentanyl with a lockout interval of 10 to 15 minutes at the discretion of an anesthesiologist who participated in the assessment of postoperative pain. Other adverse effects such as nausea, vomiting, pruritus, sedation, postoperative shivering, and respiratory depression were also evaluated and treated if necessary. Postoperative shivering was evaluated visually by a blinded research assistant. A forced-air warmer was used to warm patients with hypothermia. In cases of postoperative nausea and vomiting, pharmacologic interventions such as dexamethasone $4 \mathrm{mg}$ or ondansetron $4 \mathrm{mg}$ were used at the discretion of the designated PACU anesthesiologist.

The primary endpoint was the body temperature at $120 \mathrm{~min}$ utes after induction of anesthesia for arthroscopic shoulder surgery. Results are shown as mean \pm standard deviation (SD). Data normality was tested using the Kolmogorov-Smirnov test, and repeated measures analysis of variance (ANOVA) was used for the analysis of the normally distributed values over time, including core temperature after induction, body temperature in the PACU, mean arterial blood pressure, heart rate, and dial setting of $\mathrm{D}$-Vapor vaporizer. The student's t-test for continuous variables and the $\chi^{2}$ test or Fisher's exact test for nominal variables were performed between group GB and group GO. Statistical analysis was performed using IBM SPSS ver. 22 (IBM Corp., Armonk, NY, USA), and a value of $\mathrm{P}<0.05$ was considered statistically significant.

Table 1. Patient Characteristics and Perioperative Clinical Data

\begin{tabular}{|c|c|c|c|}
\hline Variable & Group GO $(\mathrm{n}=20)$ & Group GB $(\mathrm{n}=20)$ & $P$ value \\
\hline Age (yr) & $56.8 \pm 11.6$ & $53.7 \pm 11.7$ & 0.404 \\
\hline $\operatorname{Sex}(M / F)$ & $8 / 12$ & $9 / 11$ & 0.749 \\
\hline Height (cm) & $160.0 \pm 8.4$ & $162.5 \pm 11.0$ & 0.407 \\
\hline Weight (kg) & $60.0 \pm 11.4$ & $63.8 \pm 12.7$ & 0.452 \\
\hline ASA classification (I/II) & $10 / 10$ & $8 / 12$ & 0.751 \\
\hline Hypertension & 6 & 8 & 0.741 \\
\hline Diabetes mellitus & 3 & 6 & 0.451 \\
\hline Diagnosis/operation name & & & 1.000 \\
\hline Rotator cuff tear/ARCR & 18 & 17 & \\
\hline SLAP lesion/SLAP repair & 2 & 3 & \\
\hline Dosage of rocuronium (mg) & $57.0 \pm 9.1$ & $60.0 \pm 10.6$ & 0.344 \\
\hline Operation time (min) & $126.8 \pm 11.4$ & $129.8 \pm 12.2$ & 0.426 \\
\hline Anesthesia time (min) & $147.5 \pm 10.1$ & $150.9 \pm 12.0$ & 0.347 \\
\hline Total intravenous fluid (ml) & $307.5 \pm 18.3$ & $310 \pm 20.6$ & 0.687 \\
\hline Total irrigation fluid (L) & $11.8 \pm 5.8$ & $11.3 \pm 4.7$ & 0.784 \\
\hline Shivering in PACU & $6(30 \%)$ & $0(0 \%)$ & 0.020 \\
\hline NRS in $\mathrm{PACU}_{15 \text { min }}$ (no pain/mild/moderate/severe) & $0 / 13 / 7 / 0$ & $12 / 8 / 0 / 0$ & $<0.001$ \\
\hline
\end{tabular}

Values are means \pm SD. Group GO: patients receiving general anesthesia only, Group GB: patients receiving general anesthesia and preoperative brachial plexus block, ASA: American Society of Anesthesiologists, ARCR: arthroscopic rotator cuff repair, SLAP: superior labrum anterior-posterior, NRS: numeric rating scale, PACU: post-anesthesia care unit, NRS in PACU 15 min: NRS checked 15 minutes after admission to PACU, Mild: NRS 1-3, Moderate: NRS 4-6, Severe: NRS 7-10. 


\section{Results}

There were no significant differences in the demographic data, the duration of operations, the amount of intravenous fluid administration, or the initial body temperatures between group GO and group GB (Table 1). There were no IBPB-related complications such as pneumothorax, phrenic nerve paresis, or cervical sympathetic trunk block (miosis, ptosis, anhidrosis, enophthalmos) in group GB.

The initial body temperatures were $36.5 \pm 0.3^{\circ} \mathrm{C}$ vs. $36.4 \pm$ $0.4^{\circ} \mathrm{C}$ in group $\mathrm{GB}$ vs. $\mathrm{GO}$, respectively $(\mathrm{P}=0.215)$. After the induction of anesthesia, the core temperatures of both group decreased during the operations. The body temperature at 120 minutes after the induction of anesthesia was significantly higher in group GB than in group GO $\left(35.8 \pm 0.3^{\circ} \mathrm{C}\right.$ vs. $34.9 \pm 0.3^{\circ} \mathrm{C}$; $\mathrm{P}<0.001)$. The extent of core temperature reduction was significantly smaller in group GB than in group GO (P < 0.001; Fig. 1$)$. Warm cotton blankets were applied to 10 patients in group GO because of intraoperative low body temperatures (below $35^{\circ} \mathrm{C}$ ), while none of the patients in group GB required warm cotton blankets. When patients entered the PACU, the initial body temperatures were significantly lower in group $\mathrm{GO}\left(35.7 \pm 0.4^{\circ} \mathrm{C}\right.$ vs. $\left.35.0 \pm 0.3^{\circ} \mathrm{C} ; \mathrm{P}<0.001\right)$. The body temperatures at $60 \mathrm{~min}-$ utes after admission to the PACU were $35.8 \pm 0.3^{\circ} \mathrm{C}$ vs. $35.2 \pm$ $0.2^{\circ} \mathrm{C}$ in group $\mathrm{GB}$ vs. $\mathrm{GO}$, respectively $(\mathrm{P}<0.001)$. Both groups demonstrated a slowly increasing pattern of body temperature during the recovery period. However, the body temperature of group GB was significantly higher than that of group GO (P $<0.001)$. A forced-air warmer was applied to all patients in of group GO, while only two patients in group GB required active warming.
The concentrations of desflurane at 0,15 , and 120 minutes after induction of anesthesia were 6.0 vs. $6.0 \%(P=0.330), 5.0$ $\pm 0.8 \%$ vs. $5.8 \pm 0.4 \%(\mathrm{P}=0.001)$, and $3.4 \pm 0.4 \%$ vs. $7.1 \pm 0.9 \%$ $(\mathrm{P}<0.001)$ in group GB vs. GO, respectively. The concentration of desflurane was significantly lower in group GB compared to group GO during arthroscopy $(\mathrm{P}<0.001$; Fig. 2$)$.

The hemodynamic variables demonstrated minimal changes during the operation, as intended. The intraoperative dial setting of Dräger D-Vapor vaporizers was significantly lesser in group GB compared to group GO $(\mathrm{P}<0.001)$. There were no significant differences in muscle relaxant requirements during

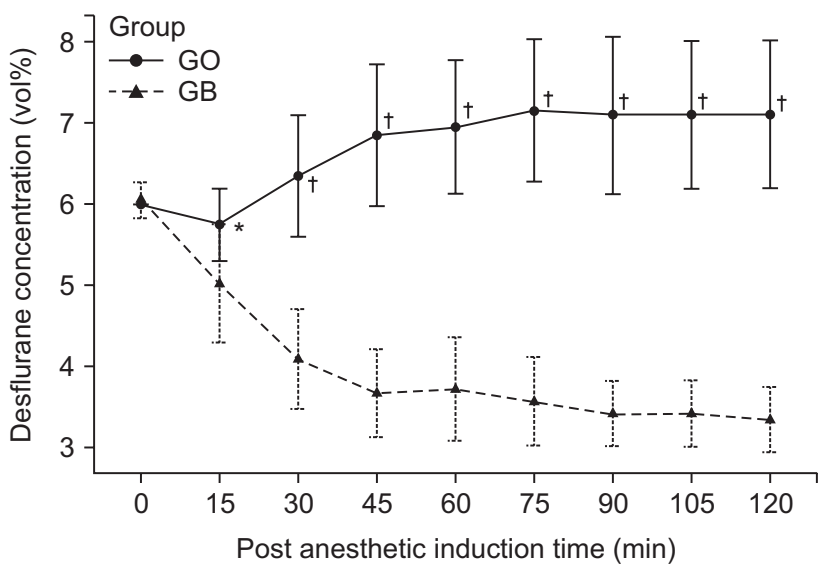

Fig. 2. Changes of desflurane concentrations during arthroscopic shoulder surgery. Group GO: patients receiving general anesthesia only, Group GB: patients receiving general anesthesia and preoperative brachial plexus block. There were significant differences in desflurane concentrations between group GO and group GB $\left({ }^{*} \mathrm{P}<0.05,{ }^{\dagger} \mathrm{P}<0.001\right.$, compared with group GB).

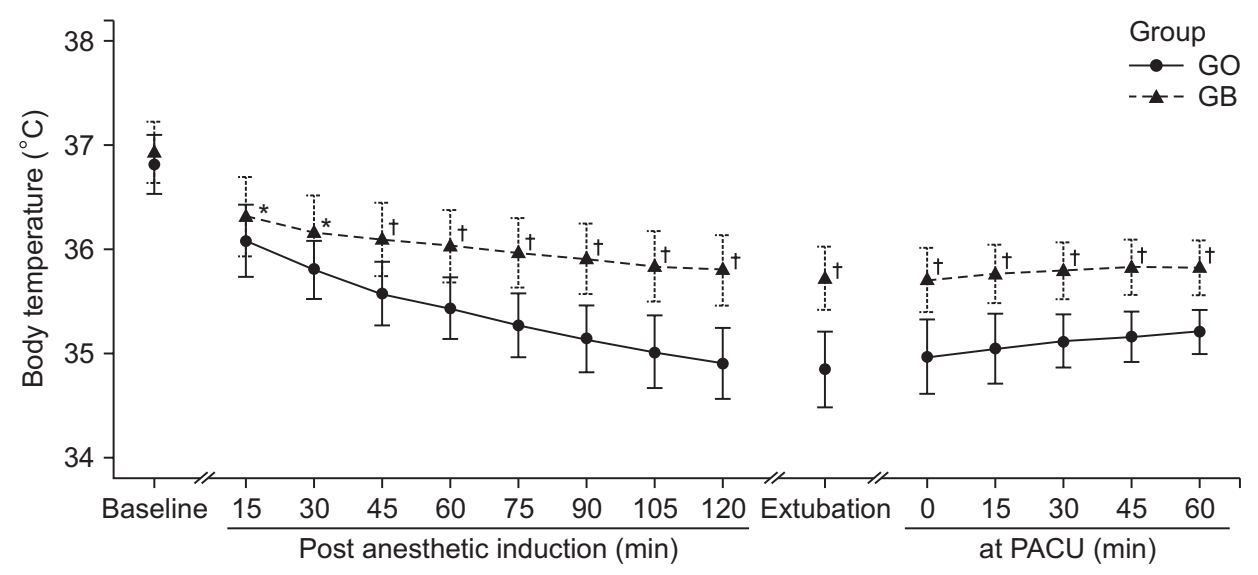

Fig. 1. Perioperative body temperature changes during arthroscopic shoulder surgery. Group GO: patients receiving general anesthesia only, Group GB: patients receiving general anesthesia and preoperative brachial plexus block. Baseline: before the induction, Post anesthetic induction: after anesthetic induction, Extubation: at the time of extubation, in PACU: after patients entered the PACU. Body temperatures were measured with a tympanic thermometer at baseline and in the PACU while others were measured with an esophageal stethoscope with a temperature sensor. There were significant differences in perioperative body temperatures between group GO and group $\mathrm{GB}\left({ }^{*} \mathrm{P}<0.05,{ }^{\dagger} \mathrm{P}<0.001\right.$, compared with group GO). 
the operation between group GB and group GO $(\mathrm{P}=0.344)$. Six patients in group GO demonstrated shivering during their stay in the PACU, while no patients in group GB complained of shivering, and there was a statistically significant difference in the incidence of shivering between the two groups $(\mathrm{P}=0.02)$. In group GB, 12 patients experienced no pain and 8 patients reported mild pain 15 minutes after admission to the PACU. In group GO, 13 patients experienced mild pain and 7 patients reported moderate pain 15 minutes after admission to the PACU $(\mathrm{P}<0.001)$.

\section{Discussion}

The present study showed that IBPB followed by general anesthesia (group GB) decreased core temperature reduction significantly compared to general anesthesia alone (group GO) during arthroscopic shoulder surgery.

Hypothermia develops during general anesthesia as a result of impaired autonomic thermoregulation and exposure to the cold environment. Although anesthetic-impaired thermoregulation has been known to be an important cause of intraoperative hypothermia, there have been few efforts to reduce anesthetics for the prevention of hypothermia out of concerns related to intraoperative awareness, movement, and other possible problems during operations. In addition to the previously mentioned factors, large amounts of cold arthroscopic irrigation fluid, used to optimize the visibility of the operative site during surgery, were thought to be among the causes of intraoperative hypothermia [2]. There have been some studies that have investigated the effect of warm irrigation fluid on the core temperature during arthroscopic shoulder surgery [2,3]. Oh et al. [2] showed that warm irrigation fluid did not decrease perioperative hypothermia during arthroscopic shoulder surgery, while the study of Kim et al. [3] found the opposite result. The effects of warm arthroscopic irrigation fluid on body temperature have been controversial, and warm irrigation fluid might be considered as an adjunct to decrease temperature reduction, but warm irrigation fluid was not relevant to anesthetic-impaired thermoregulation.

All general anesthetics are known to markedly impair normal autonomic thermoregulatory control in a dose-dependent manner [12,14-16]. That means that lower doses of general anesthetics could lead to less temperature reduction. The present study was designed to investigate the potential role of IBPB as a method to reduce the amount of inhalational anesthetics and the degree of hypothermia during general anesthesia. The results of this study showed significantly lower desflurane requirements and decreased core temperature reductions during the operation in group GB than in group GO. General anesthetics slightly increase the sweating threshold while markedly and synchronously decreasing the vasoconstriction and shivering thresholds
[12,14-16]. The combination of increased sweating threshold and reduced vasoconstriction threshold increases the interthreshold range, and temperatures within this range do not trigger thermoregulatory defenses, which means that patients are poikilothermic when their temperatures are within this range [9]. Therefore, lower desflurane usage might lead to decreases in the interthreshold temperature and consequently less temperature reduction. Core body temperature was found to correlate with the age of the patient when room temperature irrigation fluid was used [3]. Thermoregulatory function might decrease further in group GO than in group GB. However, this factor was unlikely to affect the results of the current study because there was no statistical difference in age between the two groups even though the mean age of group $\mathrm{GO}$ was higher than that of group GB. The NRS was higher in group GO than in group GB. Group GO might have a higher fentanyl requirement than group GB in the PACU. Opioids might impair the thermoregulatory response in a concentration-dependent way in the PACU [15]. However, opioids might not explain the core temperature differences during the operation in the present study.

Group GB also showed a higher body temperature than group GO in the PACU. All patients in group GO showed temperatures below $35.5^{\circ} \mathrm{C}$ and required forced-air warming, but only 2 patients in group GB required forced-air warming. It might be easier to manage the temperature of group GB than that of group GO in the PACU because the body temperature of group GB remained higher during the operation, and group GB could be considered to have higher stored thermal energy. In addition, group GB showed significantly less shivering postoperatively than group GO. Although postoperative shivering is not always associated with hypothermia, anesthetic-impaired thermoregulation best describes the shivering of these patients [17].

Shoulder surgery can be performed with regional anesthesia with IBPB alone or general anesthesia alone. However, the combination of regional and general anesthesia is preferred for the following reasons: patient discomfort due to sitting position, better and easier postoperative pain control, and additional local anesthetic infiltration is required at the posterior port site if surgery is performed with IBPB alone [18]. The present study also showed superior early postoperative pain control in group GB.

Some limitations should be considered when evaluating this study. First, cervical sympathetic involvement from IBPB might cause vasodilation of the upper extremity, head, and neck of the ipsilateral side of the block, affecting temperature measurement on the ipsilateral side of block before induction of anesthesia and in the PACU. A skin temperature thermometer on the upper extremity might be helpful to determine whether peripheral vasodilation or constriction developed [19]. Second, additional rocuronium was administered for the prevention of any patient 
movement during arthroscopic surgery with the appearance of clefts in the capnogram. Considering the effect of muscle relaxant on the BIS [20], quantitative neuromuscular monitoring should have been used for the additional muscle relaxation. Third, a forced-air warming device should have been applied to patients whenever body temperatures fell below $36.5^{\circ} \mathrm{C}$ during the operation and below $36^{\circ} \mathrm{C}$ in the PACU according to the $\mathrm{Na}$ tional Institute for Health and Care Excellence (NICE) clinical guideline 65 . This study adopted a lower temperature than that suggested in the NICE guideline before active warming measures, referring to other studies $[2,3,19,21]$.

In conclusion, the present study showed that IBPB could reduce the concentration of desflurane and decrease the degree of perioperative hypothermia during arthroscopic shoulder surgery.

\section{References}

1. Hughes MS, Matava MJ, Wright RW, Brophy RH, Smith MV. Interscalene brachial plexus block for arthroscopic shoulder surgery: a systematic review. J Bone Joint Surg Am 2013; 95: 1318-24.

2. Oh JH, Kim JY, Chung SW, Park JS, Kim do H, Kim SH, et al. Warmed irrigation fluid does not decrease perioperative hypothermia during arthroscopic shoulder surgery. Arthroscopy 2014; 30: 159-64.

3. Kim YS, Lee JY, Yang SC, Song JH, Koh HS, Park WK. Comparative study of the influence of room-temperature and warmed fluid irrigation on body temperature in arthroscopic shoulder surgery. Arthroscopy 2009; 25: 24-9.

4. Frank SM, Fleisher LA, Breslow MJ, Higgins MS, Olson KF, Kelly S, et al. Perioperative maintenance of normothermia reduces the incidence of morbid cardiac events. A randomized clinical trial. JAMA 1997; 277: 1127-34.

5. Leslie K, Sessler DI, Bjorksten AR, Moayeri A. Mild hypothermia alters propofol pharmacokinetics and increases the duration of action of atracurium. Anesth Analg 1995; 80: 1007-14.

6. Rajagopalan S, Mascha E, Na J, Sessler DI. The effects of mild perioperative hypothermia on blood loss and transfusion requirement. Anesthesiology 2008; 108: 71-7.

7. Kurz A, Sessler DI, Lenhardt R. Perioperative normothermia to reduce the incidence of surgical-wound infection and shorten hospitalization. Study of Wound Infection and Temperature Group. N Engl J Med 1996; 334: 1209-15.

8. Gentilello LM, Jurkovich GJ, Stark MS, Hassantash SA, O'Keefe GE. Is hypothermia in the victim of major trauma protective or harmful? A randomized, prospective study. Ann Surg 1997; 226: 439-47.

9. Sessler DI. Temperature regulation and monitoring. In: Miller's Anesthesia. 8th ed. Edited by Miller RD, Cohen NH, Eriksson LI, Fleisher LA, Wiender-Kronish JP, Young WL: Philadelphia, Elsevier/Saunders. 2015, pp 1624-7.

10. Annadata R, Sessler DI, Tayefeh F, Kurz A, Dechert M. Desflurane slightly increases the sweating threshold but produces marked, nonlinear decreases in the vasoconstriction and shivering thresholds. Anesthesiology 1995; 83: 1205-11.

11. Xiong J, Kurz A, Sessler DI, Plattner O, Christensen R, Dechert M, et al. Isoflurane produces marked and nonlinear decreases in the vasoconstriction and shivering thresholds. Anesthesiology 1996; 85: 240-5.

12. Sessler DI, Olofsson CI, Rubinstein EH, Beebe JJ. The thermoregulatory threshold in humans during halothane anesthesia. Anesthesiology 1988; 68: 836-42.

13. Yoo HS, Park SW, Yi JW, Kwon MI, Rhee YG. The effect of forced-air warming during arthroscopic shoulder surgery with general anesthesia. Arthroscopy 2009; 25: 510-4.

14. Matsukawa T, Kurz A, Sessler DI, Bjorksten AR, Merrifield B, Cheng C. Propofol linearly reduces the vasoconstriction and shivering thresholds. Anesthesiology 1995; 82: 1169-80.

15. Kurz A, Go JC, Sessler DI, Kaer K, Larson MD, Bjorksten AR. Alfentanil slightly increases the sweating threshold and markedly reduces the vasoconstriction and shivering thresholds. Anesthesiology 1995; 83: 293-9.

16. Talke P, Tayefeh F, Sessler DI, Jeffrey R, Noursalehi M, Richardson C. Dexmedetomidine does not alter the sweating threshold, but comparably and linearly decreases the vasoconstriction and shivering thresholds. Anesthesiology 1997; 87: 835-41.

17. Nicholau TK. The postanesthesia care unit. In: Miller's Anesthesia. 8th ed. Edited by Miller RD, Cohen NH, Eriksson LI, Fleisher LA, Wiender-Kronish JP, Young WL: Philadelphia, Elsevier/Saunders. 2015, p 2939.

18. Beecroft CL, Conventry DM. Anaesthesia for shoulder surgery. Contin Educ Anaesth Crit Care Pain 2008; 8: 193-8.

19. Jung KT, Kim SH, Lee HY, Jung JD, Yu BS, Lim KJ, et al. Effect on thermoregulatory responses in patients undergoing a tympanoplasty in accordance to the anesthetic techniques during PEEP: a comparison between inhalation anesthesia with desflurane and TIVA. Korean J Anesthesiol 2014; 67: 32-7.

20. Messner M, Beese U, Romstöck J, Dinkel M, Tschaikowsky K. The bispectral index declines during neuromuscular block in fully awake persons. Anesth Analg 2003; 97: 488-91.

21. Jo YY, Kim HS, Chang YJ, Yun SY, Kwak HJ. The effect of warmed inspired gases on body temperature during arthroscopic shoulder surgery under general anesthesia. Korean J Anesthesiol 2013; 65: 14-8. 